\title{
Technology and young children - new strategies to prevent illiteracy and create better chances of success for all
}

\author{
R. Cohen \\ 72, rue de l'Est, 92100 Boulogne, France \\ Tele and Fax +330148250319
}

\begin{abstract}
Research, both in France and in other countries, highlights the importance of the first years of life and the immense potential of young children. Educational policies need to recognize the importance of education from a very early age in order to eradicate illiteracy and allow better chances of success for all children. Young children, below age 6 , can and do take pleasure in acquiring the written language if adequate conditions for learning are provided. New horizons have now opened up with the use of Information Technology and empowering results have been obtained in classes where children use computers for the simultaneous acquisition of both the oral and written language. This paper will focus on the new strategies used to implement such an educational policy - a policy of success for all should start in preschool!
\end{abstract}

\section{Keywords}

Capacity building, elementary education, equity issues, innovation, literacy

\section{INTRODUCTION}

In all countries, whether in the developed or developing world, educational policymakers are faced with a major issue - how to create better chances of success for all children. It is essential to overcome the problem of illiteracy and school failure. Many solutions have been tried more or less successfully. Now two main research trends have opened new horizons: the importance of the first years of life and the breakthrough of technology. 
Let us focus first on the following questions: why is early education important? Is a young child able to discover written language? Is a young child able to use a computer, not only for play but for learning?

\section{THREE KEY PRELIMINARY QUESTIONS}

\subsection{Why is early education important?}

Current theories say that young children have immense potential and that their learning abilities are far greater than was believed a few years ago. But in order to develop innate talents and potential, young children need a very rich environment, stimulating experiences and appropriate motivational encouragement. B. Bloom (1964), an American psychologist, speaks of 'exceptional levels of talents (that) require certain types of environmental support'. The same belief in the power of early learning is expressed by A. Jacquard (1978), a French geneticist who believes 'every child is a potential superman: what I am, I am by virtue of heritage: what I become depends on what I do with it'. Neurobiologists indicate that, in order to function, the neurological system has to receive optimal stimulation. Intelligence develops in interaction with the environment.

Therefore it is necessary to recognize the cognitive needs of young children, their wishes and their potential to learn. All children must be provided with a very rich and stimulating environment so that they may interact, explore and thus 'construct' their knowledge. Teachers must be careful not to merely 'teach' but to create conditions so that the child is able to learn for, according to Rogers (1969) 'the more the adult teaches the less the child learns'.

\subsection{Is a young child able to discover written language?}

It is no longer a question if a child should or should not, can or cannot, read before age 6 . Research in many different countries has demonstrated that very young children enjoy discovering and using the written language (Cohen, 1977, 1982, Cohen and Gilabert, 1986). The problem is 'how' young children learn to read. Teachers using traditional methods often meet with little success with a number of students in spite of their efforts, professional skills and personal qualities.

The problem is a methodological one - not 'to teach reading' but to let the child discover the written language as $\mathrm{s} /$ he has discovered the oral language, in a natural way. In countries which have a long oral tradition of oral literacy, oral and written expression can thus be developed simultaneously.

It is not my purpose to develop the methodology of reading in this discussion but to explain that when we speak of written language we assume that it implies receiving messages (reading) and sending messages (writing). What has long prevented the acceptance that young children before age 6 are able to use the written language is the confusion between reading and writing capabilities. Of course, young children are not able to write readable messages because they lack motor coordination. But they love telling stories; their imaginations are active. They draw and scribble. But they are also ABLE to read, which means receive messages from the outside world! What if a special device should allow children to send 
messages in such a way that they are not hindered in their ability to express themselves and be read by others?

\subsection{Is the young child able to use a computer not only for play but for learning?}

Information Technology has been responsible for a breakthrough in the world of young children, particularly in the area of reading. International research has shown that, whatever the country, the language of instruction or the social environment, the use of new technologies by young children has brought about important changes in our perception of learning theories, of the process of acquisition of the written language and the development of capabilities considered unusual at such an early age. Bringing learning theories into question is a real challenge but preventing illiteracy, school failure and giving an equal chance to all children is an even greater challenge. This is what research into the use of IT for young children is all about.

Over the last ten or fifteen years, international research has demonstrated that young children are not only able to use a computer in play activities but also for working purposes (Cohen, 1987; 1992; 1993). One can argue that spending time and money to equip preschools and train teachers is not a priority, particularly in developing countries where emphasis should first be given to high schools.

Research has shown that using computers allows young children not only to acquire fundamental knowledge for their future such as reading and writing but also develops mental abilities and basic skills which will transfer in other fields of activities thus preventing failures. Furthermore, being computer literate is easy for youngsters and allows them better school performances in the next years of their schooling. Thus spending time and money on young children means gaining time and money later.

The main questions are now: How should IT be used in a classroom for young children? What learning situations are likely to enhance creative and autonomous learning? What kind of new opportunities should we offer children? What is the role of the teacher?

\section{3}

\section{COMPUTERS IN THE CLASSROOM}

It is clear that introducing IT to young children brings about important changes, not only in the type of materials offered to the children but also in the way these materials are used in a creative way. Traditional ways of teaching cannot fit into the new learning situations which integrate text, images, movement and voice, and which promote the autonomous search for information and communication with other children all over the world. Teachers must be prepared to face real changes in their role and must understand how much more effective learning is in the new conditions. It is as much a challenge for them as it is for the children.

Two excellent books (Downes and Fatouros, 1995; Casey, 1997) give a broad picture of new opportunities, areas and means for learning. They give precious practical advice for the use of IT in elementary classrooms. Casey shows the magnitude of the problem when she quotes Negroponte (1995): 'Computing is not 
about computers anymore. It is about living. Schools will change to become more like the museums and playgrounds for children to assemble ideas and socialize with other children all over the world'.

It will not be easy to make drastic shifts in our educational systems and it is not the scope of this discussion to suggest how those shifts might occur. Nor can we give detailed practical advice, list the necessary equipment or suggest specific software programs that may be used. Instead, let's focus on using computers in preschools and elementary classes as we have experienced it over the years.

\subsection{Organizing the environment}

Even if teachers do not have high tech equipment or many computers, excellent work can be achieved all the same. Even one computer in the classroom, if used wisely, can make a major difference if considered as one among other opportunities to learn, albeit a valuable and selected one because of its high potential for motivating children to communicate. The 'computer corner' is one corner among the others - the painting corner, block corner, book corner and other spaces for enquiry - which children can choose freely, all during the day. Activities using the computer are integrated with other classroom activities and organized around a common topic or center of interest. In no way must we drive very young children to drill and practice activities nor drag them to a computer lab on a certain day and at a certain hour. Equipment should be available at all times if creativity is to be encouraged.

The classroom organization - and particularly the computer corner - should allow for independent and autonomous work as well as for group work and cooperative learning, which even young children are capable of assuming by themselves. Charts explaining the work to be done and rules to observe in the computer corner can be pinned on the wall. Children develop their own methods of work, share their experiences and become more and more efficient as a variety of settings are provided for them. Interactions between children - made easy around a computer because children can cooperate with one another as they work - enhances effective learning. The cooperative learning environment encourages self-learning and self-organization as well as self-esteem. In fact, a child should never face failure. Good software allows self-correction and the use of the delete key, and group learning will give all children opportunities to avoid and/or correct mistakes, thus leading them to successful results.

Thus the way the computer corner is organized as well as the materials offered should allow open exploration, experimentation and creativity (Vygotsky, 1978). Never should the teacher decide beforehand what the children are capable of doing, what they should learn, or when and how they should learn. Teachers should not set limits but open spaces in the classroom for the development of higher psychological processes (Papert, 1980). Who would have believed that young children were capable of using a keyboard at the age of three? Our findings, as well as others' research shows that this is not only possible but benefits their mental and social development (Lawler, 1985).

Let us take an example. The children, aged 4 and 5 , went to visit the zoo this morning. On their return, they speak about their visit and the teacher writes down their sentences. They draw, paint the animals they saw and learn about each of 
them, finding information in dictionaries, books, films but also using the World Wide Web when the class is equipped for the Internet. They listen to stories such as the Jungle Book or The Lion King, or other stories and folk tales. But they can also, on the computer, draw and write about their visit or their individual stories. How to achieve this when one is 4 or 5 years old? Even if they do not know the alphabet yet our experience has shown that they can copy the sentences the teacher has taken down on a sheet of paper. Gradually they will learn the names of the letters and learn at the same time the spelling of the words. In doing this, they can help each other if they work in groups and/or copy what the teacher has written if their expertise in writing is not enough developed yet. Then they can print what they have written and thus make their own reading books.

A very important feature of children's computer use is that information is gathered in various forms - not only written information but also pictures and sound when available in the IT environment. The same is true of the different means the children will choose to express themselves. They should all have equal opportunities to use their talents so mastery is no longer in the hands of those who write well.

Information can also be obtained from different sources; some are remote but can still be reached easily. Hypertext reading is understood by young children and is great fun for them. They can also share their experiences with other friends all over the world by using network and telecommunications, which enhances curiosity for other countries and international understanding.

\subsection{Organizing time}

If space is to be organized, so must time. Children are so enthusiastic when they use computers that they tend to stay at the computer for long periods, forgetting that others are eager to have access. Individuals and/or groups of two or three children should be able to take turns. Even then, independent and self pacing activities should be organized by using a timer or some other strategy. In fact, as work develops, children's attention spans and concentration increases, and so does the speed of the learning process. We have observed children under 5 staying more than 45 minutes at the computer!

\subsection{Work and play}

When children are happy and take pleasure in what they are doing, when they concentrate and are attentive, is that play or work? In such situations the line between play and work is difficult to establish. What is certain is that if all activities are presented in a playful manner children will not show reluctance, especially if they are allowed to share their work with friends. Laughter and constant exchanges around the computer centre prove that this is a happy experience for the children, a major condition for stimulation and learning. 


\subsection{The role of the teacher}

In self-learning situations the role of the teacher must change. His/her role is no longer to teach a class but to organize an environment where children can learn. The teacher provides the learning materials, organizes space and time, and sets out the storage spaces and rules in the classroom. He/she becomes a guide, a partner, a friend. Changes in the teacher's role do not mean the teacher loses authority. On the contrary, the teacher grows in the esteem of the children as he/she shares power with them. Thus the relationship with the students changes for it is they who have become the main actors in building up their knowledge.

The relationship with other colleagues also changes as teachers must cooperate. In many cases exchanges between different classes will take place as grouping by activities will replace grouping by age. The children might also go to different classrooms according to the different activities in which they are involved. Flexibility of time, space and grouping are useful rules to be observed.

\section{USING COMPUTERS FOR THE ACQUISITION OF WRITTEN LANGUAGE}

Now let us focus on the written language and ask ourselves what contributions and changes the use of computers bring about in the acquisition of written language by young children. If I use the words 'written language' in place of 'reading' and 'writing', it is because the terms highlight the idea that written language is a communication process and the computer offers young children very specific opportunities in this respect. First of all, their productions are neat, clear and readable by everyone. The children can correct their work but the text always looks 'pretty'. It can be printed and sent to others. Children do not read or write for their teachers but for themselves.

Computers lead children to important self discoveries in the use of written language - first, the direction and spatial structure of the writing becomes clear as the screen is filled from left to right, at least for languages such as French, English or German. Second, the use of spaces allows children to understand what a word is, and then the use of the letters on the keyboard, which allows them to learn the letters. In short, the written language is, from the very beginning, accessible to young children who are no longer prisoners of their motor skills and capabilities. Writing becomes very early a mode of self expression and communication.

Voice output is of special importance (Cohen, 1992; 1993). Some software programs allow children to listen to each letter or word they type. They can also listen to the whole text if they wish. In the case of 'speaking' software such as CDROMs, the story, text or pictures become self-explanatory. The children build their own stories by clicking on different objects, the story is written as the action appears on the screen and if they are unable to read the story, they can click on the difficult words and hear them.

The use of voice output enhances children's awareness of language and increases the speed of language acquisition. It encourages self -learning and acts permanently as positive feedback. More importantly, the voice output makes a fundamental contribution to foreign language learning and gives young children access 
simultaneously to the oral and written features of a second language. Here we raise a problem that, in classical education, has been approached quite differently and in so doing we are upsetting firmly-rooted beliefs. It is generally believed that young children should first learn to speak a foreign language before they learn how to write and read it. In our experience, many of our young children were nonfrancophone. For them French was a foreign language. But using a computer equipped with a voice synthesizer made them acquire both oral and written French simultaneously and without difficulty before age 6 .

\section{5}

\section{CONCLUSION}

The joy and enthusiasm observed in computer-based activities leads us to think that computers may be a very 'good thing' for young children and that the written language can be acquired just as easily as the oral language without tedious repetitions or predefined progression. In our experience, children using computers have increased their language abilities and have become interested in sentences, spelling and punctuation much earlier than what is generally considered as 'usual'.

The pleasure of the children proves that what we are really providing is a response to a deep need of the child - learning - allowing for the development of many different kinds of personal strategies and creativity. Children will master the written language as they have mastered the oral language, by using it. What was considered difficult for children is within their reach! More than knowledge, what we are promoting is children's personal development to help them achieve all their inner capabilities and talents.

The results of international research in the field of computers and IT use by young children challenge what we thought were accepted theories of learning. More importantly, they open up new outlooks for all children, demonstrating that young children can acquire the written language at an early age in a constructive and fruitful way.

To equip high schools with IT is a good thing; to equip preschools and elementary classes is essential. But hardware and proper software are not sufficient. It is not easy to implement a policy of providing very young children with IT. Training of teachers, initially and then as continuous process, is basic to their successful understanding of their changing role and responsibilities. Knowing how to use the equipment is not enough. Teachers should be prepared to change their ways in a classroom. Not only should they be followed by a computer specialist during the first months to help them solving practical problems but group work should be organized among the teachers - exchange of experiences, documents and solving problems together. This practice has proved to be very beneficial and is essential to implement, promote and maintain such projects.

The new approach to education concerns all actors involved in the educational process - policy makers, educationalists, head of schools, counselors, teachers and parents. The goal is crucial and is the basis of a policy promoting equity among all children, creating for each of them better chances of success. 
Bloom, B. (1964) Stability and Change in Human Characteristics. John Wiley \& Son, New York.

Casey, J.M. (1997) EarlyLiteracy: The Empowerment of Technology. Teacher Ideas Press, Englewood, Colorado.

Cohen, R. (1st ed. 1977; 5th ed. 1992) l'Apprentissage Precoce de la Lecture, a Six Ans Est-il Deja Trop Tard? Presses Universitaires de France, Paris. Translated into Spanish ,Italian, Portuguese, Bulgarian and Greek.

Cohen, R. (1st ed. 1982, 2nd ed. 1986) Plaidoyer pour les Apprentissages Precoces. Presses Universitaires de France, Paris. Translated into Italian and Spanish.

Cohen, R. and Gilabert, H. (1st ed. 1986, 2nd ed. 1988) Decouverte et Apprentissage du Langage Ecrit Avant Six Ans. Presses Universitaires de France, Paris. Translated into Spanish and Portuguese.

Cohen, R. (ed.) (1987) Les Jeunes Enfants, la Decouverte de l'Ecrit et l'Ordinateur. Presses Universitaires de France, Paris.

Cohen, R. (ed.) (1992) Quand l'Ordinateur Parle. Presses Universitaires de France, Paris.

Cohen R. (1993) The use of voice synthesizer in the discovery of the written language by very young children. Computers in Education, 21(1/2), 25-30.

Downes, T. and Fatouros, C. (1995) Learning in an Electronic World. Primary English Teaching Association, Newton, Australia.

Jacquard, A. (1978) Eloge de la Difference. Seuil, Paris.

Lawler, R.W. (1985) Computer Experience and Cognitive Development : A Child's Learning in a Computer Culture. Chichester, Ellis Horwood, Ltd.

Negroponts, N. (1995) Being Digital. New York, Random House.

Papert, S. (1980) Mindstorms: Computers and Powerful Ideas. Basic Books Inc., New York.

Rogers, C.R. (1969) Freedom to Learn. Charles E. Merrill Publishing Co, London.

Vygotsky, L.S. (1978) Mind in Society. (eds. Cole , M., John-Steiner, V., Scriber, S., Souberman, E.) Harvard University Press, Cambridge, MA.

In spite of an MA in Philosophy and Psychology, Rachel Cohen started her career as a kindergarten teacher because of her great interest in early childhood education and strong belief in young children's potential. A full-time researcher at University Paris Nord, she explored the influence of early learning on children's development as means to prevent school failure and illiteracy. Her research includes the study of early reading, multilingualism, international education and the use of new technologies in education - both with young children using computers and adolescents using telecommunications.

She is the co-founder and first president of the European Institute for the Development of All Children's Potential (IEDPE), created in Paris, France in 1989. 